\title{
Human skeletal dysplasia caused by a constitutive activated transient receptor potential vanilloid 4 (TRPV4) cation channel mutation
}

\author{
Sang Sun Kang ${ }^{1,4}$, Sung Hwa Shin ${ }^{1}$, \\ Chung-Kyoon Auh ${ }^{3}$ and Jaesun Chun ${ }^{2}$ \\ ${ }^{1}$ Department of Biology Education \\ Chungbuk National University \\ Cheongju 361-763, Korea \\ ${ }^{2}$ Department of Biology Education \\ Korea National University of Education \\ Cheongwon 363-791, Korea \\ ${ }^{3}$ Department of Biological Science \\ Mokpo National University \\ Muan 534-729, Korea \\ ${ }^{4}$ Corresponding author: Tel, 82-43-261-3278; \\ Fax, 82-43-271-0526; E-mail, jin95324@ cbu.ac.kr \\ http://dx.doi.org/10.3858/emm.2012.44.12.080
}

Accepted 29 September 2012

Available Online 8 November 2012

Abbreviations: BRAC3, brachyolmia type 3; CMT2C, Charcot-MarieTooth disease type 2C; COPD, chronic obstructive pulmonary disease; DSMAC, distal spinal muscular atrophy congenital non-progressive; FDAB, familial digital arthropathy-brachydactyly; HEK293 cells, human embryonic kidney 293 cells; HMSN2C, hereditary motor and sensory neuropathy, type IIC; MIM, mendelian inheritance in man; MTD, metatropic dysplasia; PSTD, parastremmatic dwarfism; SEDM, spondyloepiphyseal dysplasia Maroteaux type; SMA, spinal muscular atrophies; SMDK, spondylometaphyseal dysplasias Kozlowski type; SPSMA, scapuloperoneal spinal muscular atrophy; TRP, transient receptor potential; TRPV, vanilloid receptor-related TRPs

\begin{abstract}
The transient receptor potential vanilloid 4 (TRPV4) cation channel, a member of the TRP vanilloid subfamily, is expressed in a broad range of tissues where it participates in the generation of $\mathrm{Ca}^{2+}$ signals and/or depolarization of the membrane potential. Regulation of TRPV4 abundance at the cell surface is critical for osmo- and mechanotransduction. Defects in TRPV4 are the cause of several human diseases, including brachyolmia type 3 (MIM:113500) (also known as bra-
\end{abstract}

chyrachia or spondylometaphyseal dysplasia Kozlowski type [MIM:118452]), and metatropic dysplasia (MIM:156530) (also called metatropic dwarfism or parastremmatic dwarfism [MIM:168400]). These bone dysplasia mutants are characterized by severe dwarfism, kyphoscoliosis, distortion and bowing of the extremities, and contractures of the large joints. These diseases are characterized by a combination of decreased bone density, bowing of the long bones, platyspondyly, and striking irregularities of endochondral ossification with areas of calcific stippling and streaking in radiolucent epiphyses, metaphyses, and apophyses. In this review, we discuss the potential effect of the mutation on the regulation of TRPV4 functions, which are related to human diseases through deviated function. In particular, we emphasize how the constitutive active TRPV4 mutant affects endochondral ossification with a reduced number of hypertrophic chondrocytes and the presence of cartilage islands within the zone of primary mineralization. In addition, we summarize current knowledge about the role of TRPV4 in the pathogenesis of several diseases.

Keywords: genetic diseases, inborn; osteochondrodysplasias; osteogenesis; phosphorylation; TRPV cation channels

\section{Introduction}

The transient receptor potential vanilloid 4 (TRPV4) cation channel, a member of the TRP vanilloid subfamily, is expressed in a broad range of tissues, where it contributes to the generation of a $\mathrm{Ca}^{2+}$ signal and/or the depolarization of membrane potential (Vennekens et al., 2008; Everaerts et al., 2010; Verma et al., 2010; Lewis et al., 2011; Chun et al., 2012). TRPV4 is a polymodal $\mathrm{Ca}^{2+}$-permeable cation channel of 871 amino acid (Delany et al., 2001; Watanabe et al., 2002b). It shows a very prominent outward rectification, rarely opening upon hyperpolarization (Voets et al., 2005; Loukin et al., 2010a). Mutational analyses suggest that outward 
rectification is governed by a gating mechanism independent of the main intracellular gates (Kim et al., 2010; Loukin et al., 2010a).

The predicted TRPV4 structure harbors six membrane-spanning domains with a pore loop, an $\mathrm{N}$-terminal domain with at least three ankyrin repeats, and a C-terminal domain residue within the cytoplasm (Delany et al., 2001; Watanabe et al., 2002b; Voets et al., 2005; Loukin et al., 2010a). These characteristics are common features in all six TRPVs (TRPV1-6) (Vennekens et al., 2008; Everaerts et al., 2010; Chun et al., 2012). Although the TRPV family shows similar characteristics, each member has its own distinguishable functions from other TRPVs (Figure 1).

The participation of TRPV4 in osmo- and mechanotransduction is relevant to several important functions, including cellular and systemic volume homeostasis, arterial dilation, nociception, bladder voiding, and the regulation of ciliary beat frequency (Suzuki et al., 2003b; Andrade et al., 2005; Becker et al., 2005; Earley et al., 2005; Birder et al., 2007; Hartmannsgruber et al., 2007). TRPV4 channel activity can be sensitized by the co-application of a

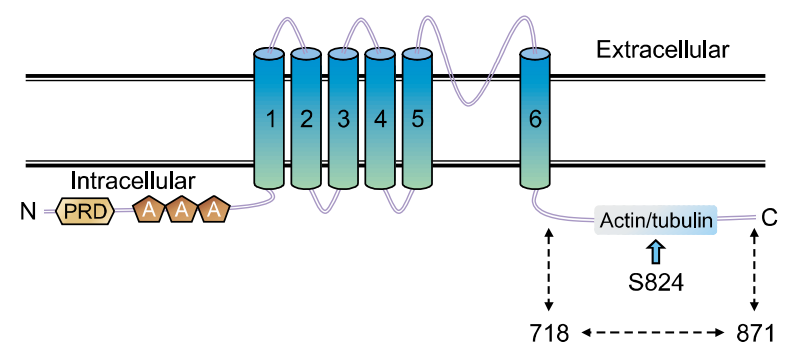

Figure 1. The TRPV4 topology and its domains. Transmembrane topology of the mouse TRPV4 (871 amino acids length). Indicated are the three ankyrin-binding repeats (ANK; as pentagon), the six trans-membrane regions (TM1-TM6), the $\mathrm{Ca}^{2+} / \mathrm{F}$-actin- or microtubule-binding site (F-actin or microtubule), and the putative SGK1 phosphorylation site (S824) which is indicated by the arrow type (WT; Gene Bank \#.

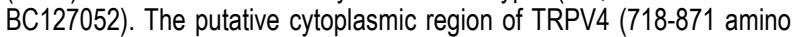
acids) is also indicated by underlining. variety of stimuli and by the participation of a number of cell signaling pathways, which suggests the presence of different regulatory sites (Nilius et al., 2004; Shin et al., 2012). In this regard, several proteins have been proposed to modulate TRPV4 subcellular localization and/or function, including microtubule-associated protein 7, calmodulin, F-actin, and pacsin3 (Strotmann et al., 2003; Suzuki et al., 2003a; Cuajungco et al., 2006; Ramadass et al., 2007); (Table 1). A functional and physical interaction between inositol trisphosphate receptor 3 and TRPV4 has been demonstrated, which sensitizes the latter to the mechano- and osmotransducing messenger, 5'-6'-epoxieicosatrienoic acid (Vriens et al., 2005; Fernandes et al., 2008). TRPV4 is also responsive to temperature, endogenous arachidonic acid metabolites, and phorbol esters, including 4- $\alpha$ phorbol 12, 13-didecanoate (4- $\alpha$ PDD), and participates in receptor-operated $\mathrm{Ca}^{2+}$ entry, thus, possessing multiple activation modes (Guler et al., 2002; Watanabe et al., 2003; Jia et al., 2004); (Table 2). However, the precise manner in which TRPV4 is

Table 1. Amino acid sequences of binding domain in TRPV4 for various interacting proteins

\begin{tabular}{lc}
\hline \multicolumn{1}{c}{ Protein } & $\begin{array}{c}\text { Binding site } \\
\text { (amino acids \# in 871 amino acids) }\end{array}$ \\
\hline -catenin, E-cadherin & $1-235$ \\
Pacsin3 (syndapin3) & $131-144$ \\
PACS-1/AP-1 & $171-190$ \\
Ankyrin & $236-390$ \\
OS-9 & $438-468$ \\
MAP7 & $789-809$ \\
IP3 receptor & $811-840$ \\
Calmodulin & $811-830$ \\
Actin/tubulin & $798-809$ \\
Homo tetramer & $236-390$ \\
Aquaporin 4 & Unknown \\
\hline
\end{tabular}

The protein and its binding site are summarized from the literatures in Reference Section.

Table 2. Various modification sites in TRPV4 (871 amino acids)

\begin{tabular}{lll}
\hline \multicolumn{1}{c}{ Modification } & Site (amino acid \#) & Enzyme \\
\hline Phoshorylation on Ser/Thr & S88, S134, S528, S824 & PKC \\
& S824 & SGK1 \\
Phoshorylation on Tyr & Y253 & Lyn \\
S-nitrosylation & C853 & Endoglycosidase-F \\
N-glycosylation & N651 & \\
Small ligand binding site & & \\
Gallic & C194 & \\
4-a PDD & L584, W586 & \\
Capsaicin & Y556
\end{tabular}

The modification and its amino acid position are summarized from the literatures in Reference Section. 
Table 3. TRPV4 mutant and its genetic disorder

\begin{tabular}{|c|c|c|c|c|c|c|}
\hline & Mutation & Residue & Change in charge & $\begin{array}{l}\text { Domain/motif } \\
\text { effected }\end{array}$ & $\begin{array}{l}\text { Effects on ion } \\
\text { conductivity }\end{array}$ & Genetic disorder \\
\hline 1 & C144T (exon 2)- & P19S & Nonpolar to polar & $\mathrm{N}$-terminal & Less conductivity & Hyponatermia COPD \\
\hline 2 & - & G78W & & $\mathrm{N}$-terminal & & Fetal Akinesia \\
\hline 3 & C366T (exon 2) & T89l & $\begin{array}{l}\text { Polar (uncharged) to } \\
\text { nonpolar }\end{array}$ & $\mathrm{N}$-terminal & Not done & Metatropic dysplasia \\
\hline 4 & G547A (exon 3) & E183K & Negative to plus & ARD1 & Not done & SEDM-PM2 \\
\hline 5 & A590G (exon 4) & K197R & Plus to plus & ARD2 & Not done & Metatropic dysplasia \\
\hline 6 & - & L199F & Nonpolar to aromatic & ARD2 & Not done & Metatropic dysplaisa \\
\hline 7 & ${ }^{*} \mathrm{G} 806 \mathrm{~A}($ exon 5) & $\mathrm{R} 269 \mathrm{H}$ & Plus to plus & ARD3 & $\begin{array}{l}\text { Less membrane } \\
\text { localization and } \\
\text { less conductance }\end{array}$ & SMA or HMSN2C \\
\hline 8 & C805T, *G806A (exon 5) & $\begin{array}{l}\text { R269C, } \\
\text { R269H }\end{array}$ & Plus to polar un charged & ARD3 & More conductivity & CMT2C \\
\hline 9 & & G270V & Nonpolar to polar & ARD3 & Less conductivity & FDAB \\
\hline 10 & & $\mathrm{R} 271 \mathrm{P}$ & Plus to nonpolar & ARD3 & Less conductivity & FDAB \\
\hline 11 & & F273L & Aromatic to nonpolar & ARD3 & Less conductivity & FDAB \\
\hline 12 & - & K276E & & ARD3 & & Fetal Akinesia \\
\hline 13 & - & E278K & Negative to plus & ARD3 & Not done & SMDK \\
\hline 14 & - & T295A & $\begin{array}{l}\text { Polar (uncharged) to } \\
\text { nonpolar }\end{array}$ & ARD4 & Not done & Metatropic dysplaisa \\
\hline 15 & C943T (exon 6) & R315W & Plus to aromatic & ARD4 & Less conductivity & HMSN2C \\
\hline 16 & C946T (exon 6) & R316C & Plus to polar (uncharged) & ARD4 & Less conductivity & HMSN2C \\
\hline 17 & A1080T (exon 6) & I331F & Nonpolar to aromatic & ARD5 & Not done & Metatropic dysplasia \\
\hline 18 & - & I331T & $\begin{array}{l}\text { Nonpolar to polar } \\
\text { (uncharged) }\end{array}$ & ARD5 & Not done & Metatropic dysplasia \\
\hline 19 & A992G (exon 6) & D333G & Negative to nonploar & ARD4 & More conductivity & SMDK \\
\hline 20 & - & V342F & Nonpolar to aromatic & ARD5 & Not done & Metatropic dysplasia \\
\hline 21 & - & F592L & Aromatic to nonpolar & TM4 & Not done & Metatropic dysplasia \\
\hline 22 & G1781A (exon 11) & $\mathrm{R} 594 \mathrm{H}$ & Plus to plus & TM4 & More conductivity & SMDK \\
\hline 23 & A1805G (exon 11) & Y602C & Aromatic to polar & TM4-TM5 & Not done & SEDM-PM2 \\
\hline 24 & C1812G (exon 11) & I604M & Nonpolar to nonpolar & TM4-TM5 & Not done & Metatropic dysIpasia \\
\hline 25 & G1847A (exon 12) & R616Q & Plus to polar uncharged & TM5, pore region & More conductivity & Brachylomia \\
\hline 26 & C1851A (exon 12) & F617L & Aromatic to nonpolar & TM5, pore region & Not done & Metatropic dysplasia \\
\hline 27 & T1853C (exon 12) & L618Q & $\begin{array}{l}\text { Nonpolar to polar } \\
\text { (uncharged) }\end{array}$ & TM5, pore region & Not done & Metatropic dysplasia \\
\hline 28 & G858A (exon 12) & V620I & Nonpolar to nonpolar & TM5, pore region & More conductivity & Brachylomia \\
\hline 29 & - & M625I & Nonpolar to nonpolar & TM5, pore region & More conductivity & SMDK \\
\hline 30 & - & L709M & Nonpolar to nonpolar & TM5, pore region & More conductivity & SMDK \\
\hline 31 & C2146T (exon 13) & A716S & Nonpolar to polar & $\begin{array}{l}\text { Cytoplasmic side } \\
\text { of TM6 }\end{array}$ & Same as wild type & SMDK \\
\hline 32 & - & T740I & & C-terminal region & & Fetal Akinesia \\
\hline 33 & - & R775K & Plus to plus & C-terminal region & Not done & Metatropic dysplasia \\
\hline 34 & - & C777Y & $\begin{array}{l}\text { Polar (uncharged) to } \\
\text { aromatic }\end{array}$ & C-terminal region & More conductivity & SMDK \\
\hline 35 & - & E797K & Negative to plus & C-terminal region & More conductivity & SMDK, PSTD \\
\hline 36 & - & P799R & Nonpolar to plus & C-terminal region & More conductivity & SMDK, PSTD \\
\hline 37 & - & P799S & $\begin{array}{l}\text { Nonpolar to polar } \\
\text { (uncharged) }\end{array}$ & C-terminal region & Not done & Metatropic dysplasia \\
\hline 38 & - & P799A & Nonpolar to nonpolar & C-terminal region & Not done & Metatropic dysplasia \\
\hline 39 & C2396T (exon 15) & P799L & Nonpolar to nonpolar & C-terminal & Not done & SMDK \\
\hline
\end{tabular}

The disease abbreviation means below: Serum Sodium Level Quantitative Trait Locus (Hyponatermia) (the \# of MIM is not available), Chronic obstructive pulmonary disease (COPD) (the \# of MIM is not available), Brachyolmia type 3 (BRAC3) [MIM:113500], Metatropic dysplasia (MTD) [MIM:156530]; Distal spinal muscular atrophy congenital non-progressive (DSMAC) [MIM:600175]. (DSMAC is also called as Hereditary Motor and Sensory Neuropathy, Type IIC; HMSN2C or Spinal muscular atrophies (SMA), also known as hereditary motor neuropathies. Spondyloepiphyseal dysplasia Maroteaux type (SEDM) [MIM:184095]. TRPV4 mutant (E797K or P799R) causes both Parastremmatic dwarfism (PSTD) [MIM:168400] and Spondylometaphyseal dysplasias Kozlowski type (SMDK) [MIM:184252]. Charcot-Marie-Tooth disease type 2C (CMT2C) and Scapuloperoneal Spinal Muscular Atrophy (SPSMA) [MIM:606071]. Familial digital arthropathy-brachydactyly (FDAB): (the \# of MIM is not available). MIM: Mendelian Inheritance in Man. ${ }^{*}$ G806A (exon 5) mutation causes both SMA/HMSN2C and CMT2C. It is also unclear yet that the channel activity of TRPV4 R269H is increased than that of TRPV4 WT. 


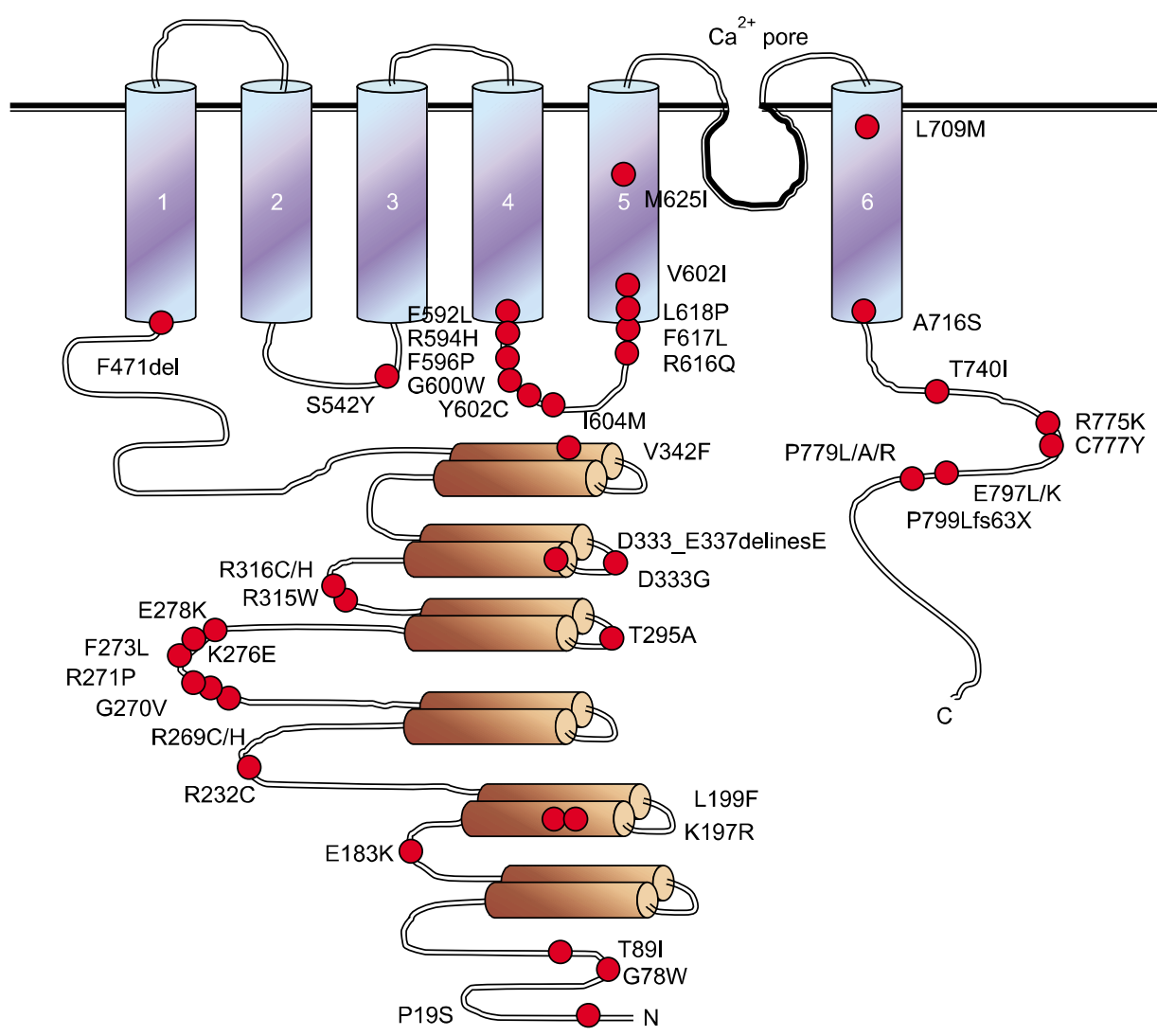

Figure 2. The naturally mutation sites on human TRPV4. Transmembrane topology of the human TRPV4 (871 amino acids length). Indicates are the three ankyrin-binding repeats (ANK; gray bar), the six trans-membrane regions (TM1-TM6), the $\mathrm{Ca}^{2+}$ pore and the mutation site (WT; Gene Bank \#. BC127052). The putative cytoplasmic region of $\mathrm{N}$-terminal (1-471 amino acids) and C-terminal (718-871 amino acids) of TRPV4 are indicated with $\mathrm{N}$ and $\mathrm{C}$. Two "hot spots" in TRPV4 sequences are prominent, one at the pore region and the other one in the between ANK 3 and 4 (del: deletion, delines: deletion or insertion extra sequence, fs: fame shift). regulated in the cell by these protein interactions, chemicals, and stimuli remains to be clearly elucidated.

Many mammalian cell types, including renal tubule cells, bronchial epithelia, keratinocytes, spermatocytes, and erythrocytes, encounter varying osmolarities in their environments (Strotmann et al., 2000; Vriens et al., 2004). The ability of these cells to adapt to changing osmotic conditions is critical for cellular homeostasis, and disequilibria can result in dramatic events, including apoptosis and necrosis. Therefore, a variety of cell types have evolved specialized mechanisms for volume regulation to counteract the damage induced by either swelling or shrinking of cells (Alessandri-Haber et al., 2003; Vriens et al., 2004). Under hypotonic conditions, cells increase their volume via water uptake mediated by the osmotic gradient. The reduction in volume to its former value is achieved by a process referred to as regulatory volume decrease (RVD), which allows cells to survive in a hypotonic environment. The direct participation of TRPV4 in RVD at the cellular level and systemic osmosensing in organisms has been demonstrated (Becker et al., 2005).

Although TRPV4 mutants develop several genetic bone diseases, including brachyolmia type 3 (BRAC3) [MIM:113500]; also known as brachyrachia and spondylometaphyseal dysplasia Kozlowski type (SMDK) [MIM:184252], and metatropic dysplasia (MTD) [MIM:156530]; also called metatropic dwarfism or parastremmatic dwarfism (PSTD) [MIM:168400], only abnormal osmotic regulation in TRPV4-/- mouse has been reported (Suzuki et al., 2003b; Verma et al., 2010; Kang, 2012); (Figure 2 and Table 3). It is currently unclear why the phenotype of TRPV4-/mice is so much different than that of TRPV4 point mutants. The TRPV4 knockout mouse phenotype does not fully recapitulate any of the human phenotypes under discussion but bladder dysfunction and hearing loss have been reported (Tabuchi et al., 2005; Gevaert et al., 2007). Defects in TRPV4 are the cause of several human diseases including BRAC3 [MIM:113500]; also known as brachyrachia or SMDK [MIM:184252], and MTD [MIM:156530]; also called metatropic dwarfism or PSTD [MIM:168400] (Auer-Grumbach et al., 2010; Dai et al., 2010; Deng et al., 2010; Landoure et al., 2010; Verma et al., 2010; Kang, 2012; McEntagart, 2012). These bone dysplasia mutants are characterized by severe dwarfism, kyphoscoliosis, distortion and bowing of the extremities, and contractures of the large joints (Figure 3 and Table 3). These diseases are characterized by a combination of decreased bone density, bowing of the long bones, platyspondyly, 


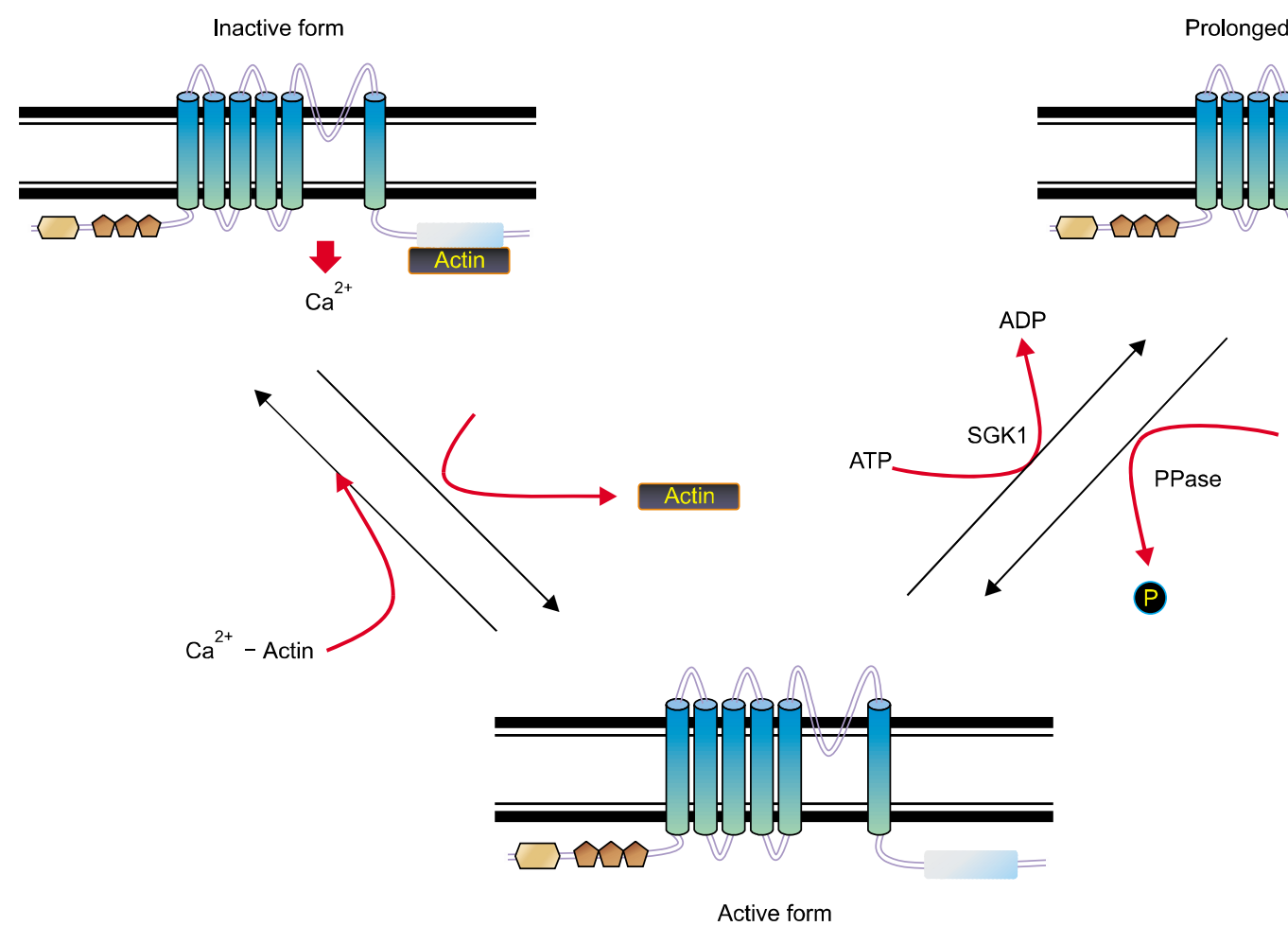

Figure 3. The scheme of proposed TRPV4 functional regulation. TRPV4 can be modulated by the putative dual (activator/inhibitor) function protein (such as F-actin or microtubule) association/dissociation from its C-terminal cytoplasmic domain (activation/inactivation) phosphorylation. After receiving a growth signal from outside, the protein kinase such as SGK1 is activated. The protein-protein interaction between TRPV4 and (F-actin or tubulin) appears to be modulated by phosphorylation on its 824 serine residue by protein kinases (right). The active TRPV4 seems to be inactivated by protein phosphatases via dephosphorylation on its Ser 824 residue (left). The inactivated TRPV4 seems to bind with tubulin (Chun et al., 2012).

and striking irregularities of endochondral ossification with areas of calcific stippling and streaking in radiolucent epiphyses, metaphyses, and apophyses (Kang, 2012; McEntagart, 2012).

Thus, in this review, the potential effect of the mutation on the regulation of TRPV4 functions is discussed, which is related to the bone diseases through its deviated function and how the mutant TRPV4 affects endochondral ossification, with reduced numbers of hypertrophic chondrocytes and the presence of cartilage islands within the zone of primary mineralization (Figure 4). With the analysis of TRPV4 mutants, we noticed the tendency that human skeletal dysplasia is caused by a constitutive activated TRPV4 mutation, but not by a constitutive inactivated mutation (Figure 5). We also realized that the seriousness of disease is dependent on its channel activity. In addition, the current knowledge about the role of TRPV4 in the pathogenesis of skeletal dysplasia is summarized (Figure 2 and Table 3).

\section{Naturally occurring TRPV4 mutants and genetic bone disorders}

Few naturally occurring TRPV4 mutants have been identified. Interestingly, most of these missense and nonsense point mutations are linked with the development of genetic disorders in humans and a detailed list of naturally occurring TRPV4 mutations and related disease has been documented (Figure 2 and Table 3). Some of these mutations that have gained importance in terms of genetic disease had been discussed (Verma et al., 2010; Kang, 2012; McEntagart, 2012).

\section{BRAC3 [MIM:113500]}

BRAC3 was characterized using a linkage analysis and candidate gene sequencing. Rock et al. (2008) found that some patients affected with brachylomia have a TRPV4 missense mutation, specifically at positions R616Q or V620I, respectively (AuerGrumbach et al., 2010; Dai et al., 2010; Deng et al., 2010; Landoure et al., 2010). These mutations are located at the fifth transmembrane region, which is a part of the functional pore. Each of these mutations 


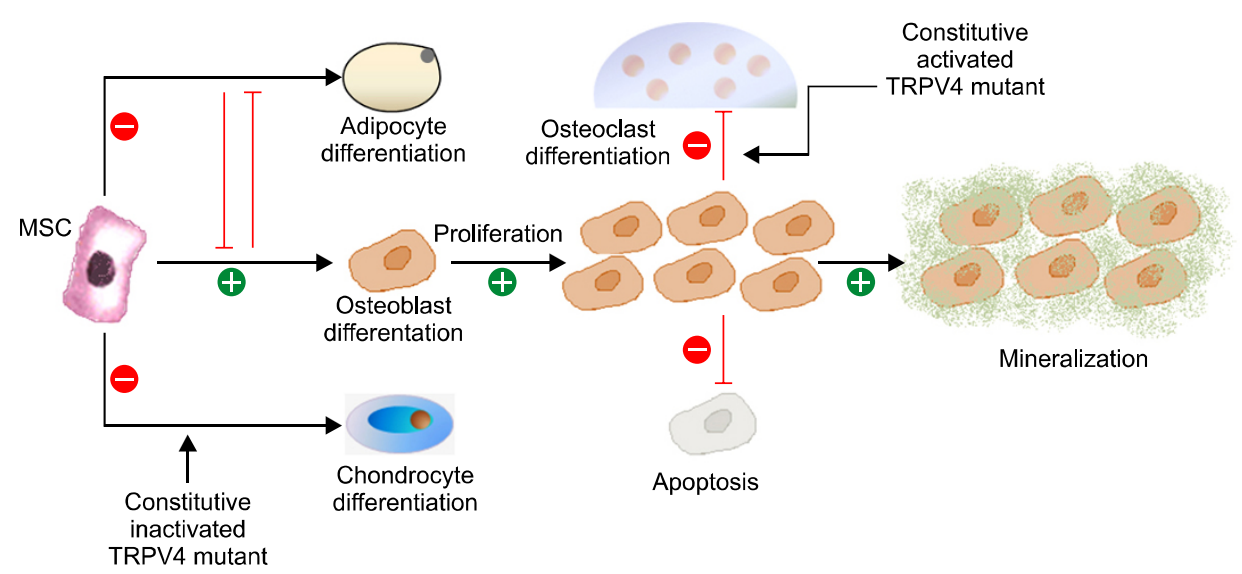

Figure 4. The osteogenesis regulation mechanisms by TRPV4 signalling. TRPV4 represses alternative mesenchymal differentiation pathways such as adipocyte and chondrocyte differentiation and promote osteoblast differentiation, proliferation, and mineralization activity while blocking osteoblast apoptosis. In this review, we hope to elucidate the etiological mechanism how the mutation in TRPV4 (E797K or P799R) causes Spondylometaphyseal dysplasias Kozlowski type (SMDK) [MIM:184252], eventually. The mutant TRPV4 which is constitutively active in HEK293 cell results in the activation of osteoclast abnormally. It is unknown yet how the constitutive active TRPV4 activates osteoclast. The research hypothesis is that the constitutive active mutant TRPV4 (such as E797K, P799R) represses the chondrocyte differentiation from MSC and promotes the osteoclast activation (or the osteoblast apoptosis) with the increase of related transcription factor, such as NFATc1 (Wegierski et al., 2006). Thus, the mutant TRPV4 containing the more channel activity than the TRPV4 WT causes the abnormality of backbone morphogenesis, meanwhile the constitutive inactive mutant TRPV4 (the less channel activity than the TRPV4 WT) causes the abnormality of articular morphogenesis or the neuropathy (FDAB or HMSN2C), which is similar with that of TRPV4 (-/-) mouse (Suzuki et al., 2003b; Verma et al., 2010; Kang, 2012).

Hypothetical etiological role of TRPV4 mutant in human genetic diseases

Osteoclast proliferation
$\begin{gathered}\text { Abnormality of backbone } \\ \text { morphogenesis } \\ \text { (cause BRAC3, MTB, PSTD } \\ \text { or SEDM) }\end{gathered}$

Figure 5. Hypothetical etiological role of gain-of-function TRPV4 mutant in human genetic diseases. The mutants containing the more channel activity than the TRPV4 wt lead the abnormality of backbone morphogenesis by the more $\mathrm{Ca}^{2+}$ influx (left). However, even though this is not completely accorded in some case yet, the mutants containing the less channel activity causes the abnormality of articular morphogenesis or the neuropathy by the less $\mathrm{Ca}^{2+}$ influx (right). Because both SMA/HMSN2C and CMT2C are caused by G806A (exon 5) mutation, presently, it is unclear whether the channel activity of mutant TRPV4 R269H is increased than that of TRPV4 WT.

increases basal level activity when compared to that of wild-type TRPV4 (TRPV4-WT). Additionally the response to 4- $\alpha$ PDD (a TRPV4 specific agonist) is greater in the mutants when compared with that in the WT. This result also indicates that these two mutations preferably stabilize TRPV4 in its "open stage" resulting in constitutive activity of the channel. BRAC3 constitutes a clinically and genetically heterogeneous group of skeletal dysplasias characterized by a short trunk, scoliosis, and mild short stature. BRAC3 is an autosomal dominant form, and patients have severe kyphoscoliosis and flattened, irregular cervical vertebrae (Loukin et al., 2011).

BRAC3, caused by the R616Q gain-of-function channel, possesses increased whole-cell current densities compared with those of WT channels (Loukin et al., 2011). A single-channel analysis revealed that $R 616 \mathrm{Q}$ channels maintain mechano sensitivity but have greater constitutive activity and no change in unitary conductance or rectification. The BRAC3 range from mild autosomal-dominant BO (brachylomia), diagnosed by a shortened spine with characteristic vertebral defects and minor defects in the long bones to MTD characterized by more prominent spine defects as well as pronounced abnormalities in the articular skeleton resulting in short dumbbell-shaped long bones, which lead to prenatal lethality in its severest form (Loukin et al., 2010b; Lamande et al., 2011; Nemec et al., 2012). The reason why TRPV4 R616Q (which shows greater constitutive activity and no change in unitary conductance or rectification) causes such a prominent phenotype is unknown. 


\section{MTD [MIM:156530]}

MTD is a clinical heterogeneous skeletal dysplasia characterized by short extremities, a short trunk with progressive kyphoscoliosis, and craniofacial abnormalities including a prominent forehead, midface hypoplasia, and a squared-off jaw (Krakow et al., 2009; Camacho et al., 2010). Dominant mutations in the gene encoding TRPV4 were identified in all 10 of a series of MTD cases, ranging in severity from mild to perinatal lethal. MTD is a severe spondyloepimetaphyseal dysplasia characterized by short limbs with limitation and enlargement of joints and severe kyphoscoliosis (Cho et al., 2012). Radiologic features include severe platyspondyly, severe metaphyseal enlargement, and shortening of long bones (Andreucci et al., 2011). TRPV4 I331F and P799L mutations are well known to induce MTD (Krakow et al., 2009; Camacho et al., 2010). As all these mutants are naturally occurring and are not embryonically lethal (as most lethal mutants may be naturally excluded from the population). Notably, none of these mutants show complete loss of their prime function, i.e., ionic conductivity (Krakow et al., 2009; Cho et al., 2012).

Several experimental results suggest that some of these mutants even have enhanced channel opening. Furthermore, they demonstrate that the lethal form of the disorder is dominantly inherited and suggest locus homogeneity in the disease (Krakow et al., 2009; Camacho et al., 2010; Andreucci et al., 2011; Cho et al., 2012). Additionally, electrophysiological studies have demonstrated that the mutations activate the channel, indicating that the disease mechanism may result from increased calcium in chondrocytes (Camacho et al., 2010). Histological studies in two cases of lethal MTD revealed markedly disrupted endochondral ossification with a reduced number of hypertrophic chondrocytes and the presence of cartilage islands within the zone of primary mineralization. These data suggest that altered chondrocyte differentiation in the growth plate leads to the clinical findings of MTD (Krakow et al., 2009; Camacho et al., 2010; Andreucci et al., 2011; Cho et al., 2012).

\section{Distal spinal muscular atrophy congenital non-progressive (DSMAC) [MIM:600175]}

DSMAC (also called hereditary motor and sensory neuropathy, type IIC; HMSN2C) is a clinically variable, neuromuscular disorder characterized by a congenital lower motor neuron disorder restricted to the lower part of the body (Auer-Grumbach et al., 2010; Deng et al., 2010; Ding et al., 2010). Clinical manifestations include non-progressive muscular atrophy, thigh muscle atrophy, weak thigh adductors, weak knee and foot extensors, minimal jaw muscle and neck flexor weakness, flexion contractures of the knees, and pes equinovarus. However, tendon reflexes are normal (Deng et al., 2010; Nilius and Owsianik, 2010; Zimon et al., 2010).

Inheritance is autosomal dominant. The R315W mutation has been identified in an unrelated family that also had HMSN2C. Auer-Grumbach et al. discovered two additional TRPV4 mutations (R269H and R316C) in affected members of three additional families with these three phenotypes, indicating that they are allelic disorders (Auer-Grumbach et al., 2010; Zimon et al., 2010). All three mutations occurred at the outer helices of the ANK4 and ANK5 domains in the $\mathrm{N}$-terminal cytoplasmic domain (Figure 2). In vitro functional expression studies in HeLa cells have shown that the mutant protein forms cytoplasmic aggregates and has reduced surface expression, as well as an impaired response to stimulus-dependent channel activity. These results suggest that the mutations interfere with normal channel trafficking and function. Furthermore, Auer-Grumbach et al. identified a different heterozygous mutation in the TRPV4 gene (R315W) in a patient with congenital distal SMA whose other family members with the same mutation had phenotypes consistent with hereditary motor and sensory neuropathy-2 or scapuloperoneal spinal muscular atrophy; thus, proving that these are allelic disorders with overlapping phenotypes (AuerGrumbach et al., 2010; Deng et al., 2010; Nilius and Owsianik, 2010; Zimon et al., 2010).

\section{Spondyloepiphyseal dysplasia Maroteaux type (SEDM) [MIM:184095]}

SEDM is a clinically variable spondyloepiphyseal dysplasia with manifestations limited to the musculoskeletal system (Dai et al., 2010; Loukin et al., 2011). Clinical features of SEDM include short stature, brachydactyly, platyspondyly, short and stubby hands and feet, epiphyseal hypoplasia of the large joints, and iliac hypoplasia, even though patient intelligence is normal (Andreucci et al., 2011). Genetic mapping of the patients affected with this disease shows a missense mutation in TRPV4 of either E183K, Y602C, or E797K (Krakow et al., 2009; Camacho et al., 2010; Dai et al., 2010; Loukin et al., 2011). The channel activity of the TRPV4 E797K mutant in HEK293 cells is constitutively active, which is consistent with the argument that effects on TRPV4 are the cause of SEDM. It is a clinically variable spondyloepiphyseal dysplasia with manifestations limited to the musculoskeletal system. Both SEDM and parastremmatic dysplasia are part of the TRPV4 dysplasia family, and TRPV4 
mutations show considerable variability in phenotypic expression resulting in distinct clinical-radiographic phenotypes (Krakow et al., 2009; Camacho et al., 2010; Andreucci et al., 2011).

\section{PSTD [MIM:168400]}

Defects in TRPV4 are also the cause of PSTD, which is a bone dysplasia characterized by severe dwarfism, kyphoscoliosis, distortion and bowing of the extremities, and contractures of the large joints (Andreucci et al., 2011). This disease is radiographically characterized by a combination of decreased bone density, bowing of the long bones, platyspondyly, and striking irregularities of endochondral ossification with areas of calcific stippling and streaking in radiolucent epiphyses, metaphyses, and apophyses (Andreucci et al., 2011; Nemec et al., 2012).

Nishimura et al. (2010) analyzed the candidate TRPV4 gene in a 7-year-old girl with PSTD and identified heterozygosity for a missense mutation $(\mathrm{R} 594 \mathrm{H})$ that had previously been found in patients with the Kozlowski type of SMDK (Nishimura et al., 2010). However, in patients with the Kozlowski type of SMDK, Krakow et al. (2009) identified a 1781G-A transition in exon 11 of the TRPV4 gene, resulting in an arg594-to-his (R594H) substitution in the cytoplasmic S4 domain (Krakow et al., 2009). Thus, both PSTD and SMDK, which are caused by the TRPV4 mutation, seem to be associated with increased basal intracellular calcium ion concentration and intracellular calcium activity. However, the Kozlowski type of SMDK is different from SEDM in the TRPV4 mutation sites (E183K Y602C, or E797K).

\section{Charcot-Marie-Tooth disease type 2C (CMT2C) and scapuloperoneal spinal muscular atrophy (SPSMA) [MIM:606071]}

CMT2C is an axonal form of Charcot-Marie-Tooth disease, a disorder of the peripheral nervous system that is characterized by progressive weakness and atrophy, initially of the peroneal muscles and later of the distal muscles of the arms (Deng et al., 2010; Landoure et al., 2010). Charcot-Marie-Tooth disease is classified into two main groups based on electrophysiologic properties and histopathology: primary peripheral demyelinating neuropathies (designated CMT1 when they are dominantly inherited) and primary peripheral axonal neuropathies (CMT2). Neuropathies of the CMT2 group are characterized by signs of axonal regeneration in the absence of obvious myelin alterations, normal or slightly reduced nerve conduction velocities, and progressive distal muscle weakness and atrophy (Bird, 1993; Nilius and Owsianik, 2010). Nerve conduction velocities are normal or slightly reduced. CMT2C and SPSMA are also known as hereditary motor and sensory neuropathy type 2 (Chen et al., 2010; Landoure et al., 2010). Patients with SPSMA are characterized by weakness of the scapularis muscle and bone abnormalities. CMT2C leads to weakness of distal limbs and vocal cords and often impairs hearing and vision. Genetic analyses of these patients have shown the presence of TRPV4 missense mutations, particularly at the $\mathrm{R} 269 \mathrm{H}, \mathrm{R} 315 \mathrm{~W}$, and R316C positions (Bird, 1993; Deng et al., 2010; Landoure et al., 2010).

\section{Familial digital arthropathy-brachydactyly (FDAB)}

FDAB is a dominantly inherited condition characterized by aggressive osteoarthropathy of the fingers and toes and consequent shortening of the middle and distal phalanges (Amor et al., 2002). Lamandé et al. showed that FDAB is caused by mutations encoding p.Gly270Val, p.Arg271Pro, and p.Phe273Leu substitutions in the intracellular ankyrin-repeat domain of the TRPV4 cation channel (Lamande et al., 2011). The TRPV4 mutant in HEK-293 cells showed that the mutant proteins have poor cell-surface localization. Those authors also suggested that TRPV4 mutations that reduce channel activity cause a third phenotype, inherited osteoarthropathy, which shows the importance of TRPV4 activity in particular cartilage homeostasis. Thus, the TRPV4 mutant (G270V, R271P, and Y273L) also seems to be related with FDAB (Nilius and Owsianik, 2010; Verma et al., 2010; Kang, 2012; McEntagart, 2012; Nemec et al., 2012).

\section{Other diseases (not included bone) with TRPV4 mutations}

Serum sodium level quantitative trait locus (hyponatremia): Tian et al. (2009) demonstrated that the rs3742030 single nucleotide polymorphism in the TRPV4 gene (P19S) is significantly associated with serum sodium concentration (Tian et al., 2009). After this discovery, hyponatremia was defined as serum sodium $<135 \mathrm{mEq} / \mathrm{L}$ in non-Hispanic Caucasian male populations. In heterologous expression studies in HEK293 cells, P19S mutant channels show a diminished response to hypotonic stress and to the osmotransducing lipid epoxyeicosatrienoic acid compared to that in WT channels (Carreno et al., 2009; Nedungadi et al., 2012). The P19S polymorphism affects TRPV4 function in vivo and likely influences systemic water balance on a population wide basis. 
Chronic obstructive pulmonary disease (COPD): COPD is characterized by airway epithelial damage, bronchoconstriction, parenchymal destruction, and mucus hypersecretion (Zhu et al., 2009; Li et al., 2011). Upon activation by a broad range of stimuli, TRPV4 functions to control airway epithelial cell volume and epithelial and endothelial permeability; it also triggers bronchial smooth muscle contraction and participates in autoregulation of mucociliary transport (Obeidat et al., 2011). These TRPV4 functions may be important for regulating COPD pathogenesis; thus, TRPV4 is a candidate COPD gene. The TRPV4 P19S mutant, which is characterized as the cause of the hyponatremia, is also observed in COPD.

Fetal akinesia: Recently, Unger et al. reported that the fetal akinesia as the presenting feature of severe metatropic dysplasia, was identified as a certain TRPV4 mutant which can cause both a skeletal and a neuropathic phenotype (Unger et al., 2011). Three cases were detected on prenatal ultrasound because of absent movements in the second trimester. The mutation of TRPV4 were confirmed the presence of de novo heterozygous mutations predicting G78W, K276E, and T740I (Figure 2 and Table 3).

\section{The TRPV4 regulatory mechanism}

The gating diversity of the TRPV4 channel demonstrated in the current study reflects the presence of multiple physical and chemical signaling pathways that converge on the channel regardless of the mechanism (Vennekens et al., 2008; Everaerts et al., 2010; Lewis et al., 2011; Chun et al., 2012). As a consequence, the TRPV4 channel appears to function as a molecular integrator of a complex array of diverse signals (Tables 1 and 2). Because multiple environmental signals and transduction pathways converge on TRPV4, the channel may function as a molecular integrator of microenvironmental chemical and physical signals. Further study to elucidate the TRPV4 regulation mechanism is required to clearly determine the physiological role and mechanism of channel activation (Delany et al., 2001; Voets et al., 2002; Watanabe et al., 2002b; Loukin et al., 2010a).

The Ser 824 residue of TRPV4 is localized within its F-actin or microtubule-binding domain (798-809 amino acids) of TRPV4 (Suzuki et al., 2003a; Shin et al., 2012). Consequently, the functional relevance of Ser 824 residue phosphorylation in the context of cytoskeletal interaction should be emphasized (Suzuki et al., 2003a; Lee et al., 2010; Chun et al., 2012; Shin et al., 2012). Thus, phosphorylation of the TRPV4 Ser 824 residue exerts a regulatory effect on its functional $\mathrm{Ca}^{2+}$ entry, protein stability, and its interactions with CaM (Figures 1 and 3), F-actin or microtubules result in an expansion of cell surface area and proper subcellular localization (Suzuki et al., 2003a; Chun et al., 2012; Shin et al., 2012).

TRPV4 channel activation and serine phosphorylation are enhanced by exposure to the non-PKC activator 4- $\alpha$ PDD or by applying bradykinin, which activates protein kinase C (PKC) or PKA via a G-protein-coupled mechanism. This enhancement was inhibited by the PKC inhibitors staurosporine, $\mathrm{BIM}$, and rottlerin, and by mutation of the serine/ threonine residues S162, T175, and S189 (Table 2). Enhancement of TRPV4 activity by S824 phosphorylation is expected to be agonized or antagonized by the selective SGK1 activity modulators (IGF2 and wortmannin) (Lee et al., 2010). However, basal activity and sensitivity to 4- $\alpha$ PDD of TRPV4 S824A (an analog of unphosphorylated TRPV4 by SGK1) was higher than those of the TRPV4 WT, suggesting that the TRPV4 C-terminal domain near the serine residue 824 was assigned to regulate its function by an unknown controlling mechanism beyond the phosphorylation modification, such as a proteinprotein interaction with CaM (Amor et al., 2002; Strotmann et al., 2003; Chun et al., 2012). Because the TRPV4 Ser824 residue has also been detected in the consensus SGK1 substrate sequences, whether or not SGK1 phosphorylates the Ser 824 residue of TRPV4, as one of its specific substrate proteins was ascertained (Figure 1 and Table 2). SGK1-mediated phosphorylation of the TRPV4 Ser 824 residue exerts a synergistic effect on functional $\mathrm{Ca}^{2+}$ entry, as well as reactivity to 4- $\alpha \mathrm{PDD}$, interactions with CaM, subcellular localization, and cell survival (Figures 1 and 2).

TRPV4 is modulated by phosphorylation of a Ser824 residue negative/positive feedback regulation loop. In a short-term regulation loop (Figure 3), TRPV4 WT appears to be dually modulated by the association of regulatory proteins (such as $\mathrm{Ca}^{2+}$ bound (aM) on its C-terminal cytoplasmic domain (Figure 1). First, the naive TRPV4 begins to open in response to several over-threshold environmental signals (e.g., mechanical chemical, temperature, and osmolality). TRPV4 is positively activated by dissociation with regulatory proteins such as $\mathrm{CaM}$ at low $\mathrm{Ca}^{2+}$ concentrations. However, the channel is negatively feedback inhibited at high $\mathrm{Ca}^{2+}$ concentrations by the fully active TRPV4 and returned to the inactive form; these mechanisms constitute the short-term negative/positive feedback regulation loop (Figure 3). This phenomenon also explains our observation that TRPV4 WT shows $\mathrm{Ca}^{2+}$ ion concentration oscillations in the cytoplasm after 
activation with 4- $\alpha$ PDD or heat. In contrast, after the TRPV4 WT is phosphorylated on its Ser824 residue by SGK1, the prolonged active (phosphorylated) form (a TRPV4 S824D analogue), which remains active until being dephosphorylated on its Ser824 residue by a protein phosphatase and the association of a putative regulatory protein (such as $\mathrm{Ca}^{2+}-\mathrm{CaM}$ ). Consistent with this assumption, TRPV4 S824D (an analogue with a prolonged active form), shows high $\mathrm{Ca}^{2+}$ channel activity with/without 4- $\alpha$ PDD treatment, abrogating the protein interaction with the inhibitory factor (Amor et al., 2002; Strotmann et al., 2003; Chun et al., 2012). This model explains why the TRPV4 E797 mutant is constitutively active. Following 4- $\alpha$ PDD or heat treatment, TRPV4 S824A appears to be analogous with its active form. TRPV4 S824A, which is not associated with the inhibitory protein $\mathrm{Ca}^{2+}-\mathrm{CaM}$ (as an inhibition complex) returns back to an inactive form (Figure 3 ). This may explain why channel activity and $\mathrm{Ca}^{2+}$ entry of TRPV4 S824A appear to be higher than those of TRPV4 WT after 4- $\alpha$ PDD treatment. However, binding of $\mathrm{Ca}^{2+}-\mathrm{CaM}$ can be prevented by SGK1-mediated phosphorylation of a serine 824 residue within the CaM binding site.

Conversely, substitution of the target site (serine 824) with aspartic acid (S824D) results in a more rapid and longer activation of TRPV4-mediated currents, as $\mathrm{Ca}^{2+}$-CaM binding can be prevented by phosphorylation (Amor et al., 2002; Chun et al., 2012; Shin et al., 2012). This convergence on a shared C-terminal domain may represent an important mechanism by which the timing and convergence of signal responses is controlled. Although $\mathrm{Ca}^{2+}-\mathrm{CaM}$ as the negative feedback regulator at high $\mathrm{Ca}^{2+}$ concentration is the focus of this research, binding competition with other proteins on the TRPV4 C-terminal region cannot be ruled out (Figure 3 ). It seems to be valuable to elucidate the protein that interacts with the C-terminal region of TRPV4.

TRPV4 harbors a consensus sequence for protein-Ser 824 phosphorylation by SGK1 within the putative CaM, actin, or tubulin binding domain (811-850 amino acids). Thus, $\mathrm{Ca}^{2+}-\mathrm{CaM}$ binding is modified by phosphorylation on Ser 824 . In this regard, the CaM binding site on its $\mathrm{C}$-termini seems to be involved in $\mathrm{Ca}^{2+}$-induced conformational changes. It is likely that the Ser 824 of the C-terminal domain induces a conformational change in the TRPV4 channel protein that results in decreased (or inactivated) channel activity, as both TRPV4 S824D, and S824A (such as the TRPV4 E797 mutant regardless of phosphorylation) are more active than that of TRPV4 WT (Amor et al., 2002; Shin et al., 2012).

A variety of stimuli activate members of the various
TRPV subfamilies. Vanilloid compounds such as capsaicin, the compound responsible for the spiciness of hot chili peppers, moderate heat, and protons activate TRPV4 channels and function as integrators of a variety of painful stimuli. Furthermore, TRPV4 is sensitive to noxious heat and can be constitutively activated by growth factors (Table 2 ).

The nitric oxide (NO) donor induces S-nitrosylation at Cys853 in the $\mathrm{C}$ terminus of TRPV4. S-nitrosylation at the Cys853 residue in the TRPV4 channel functionally and directly regulates channel sensitivity. We propose that $\mathrm{NO}$ conversely inhibits the $\mathrm{Ca}^{2+}$ response and direct S-nitrosylation on the Cys853 of TRPV4 as negative feedback regulation (Ding et al., 2010; Lee et al., 2011). Endothelial NO synthase and TRPV4 co-localize in the caveolar fraction of guinea pig hearts, thereby indicating close proximity of the NO donor and the target protein (Yoshida et al., 2006). Thus, multiple factors are responsible for making the Cys853 of TRPV4 (a target of moleculespecific and site-specific S-nitrosylation). Although TRPV5 and TRPV6 are tightly controlled by membrane potential, including a voltage-dependent open-pore block by $\mathrm{Ca}^{2+}$-dependent feedback mechanism, it is unknown whether TRPV4 is also regulated in the same manner. S-nitrosylation of the TRPV4 channel seems to be a $\mathrm{Ca}^{2+}$-dependent feedback mechanism (Figure 3). S-nitrosylation of native TRPV4 upon G protein-coupled ATP receptor stimulation elicits $\mathrm{Ca}^{2+}$ entry into endothelial cells (Yoshida et al., 2006; Ding et al., 2010). In the case of TRPV4, however, even though the increase of $\mathrm{NO}$ in cells also appears to enhance S-nitrosylation of native TRPV4, the nitrosylation site (C853) of TRPV4 is located in its C-terminal tail, and $\mathrm{Ca}^{2+}$ transport by the channel appears to be inactivated by this modification, as a negative feedback $\mathrm{Ca}^{2+}$ transport regulation mechanism. However, the fully active TRPV4 is inhibited by negative feedback at high $\mathrm{Ca}^{2+}$ ion levels and returned to the inactive form, as a negative feedback regulatory loop by NO (S-nitrosylation). Therefore, the channel properties of TRPV4 are similar those of voltage-gated $\mathrm{Na}^{+}$ channels. The various modifications of the TRPV channel C-terminal are summarized in Table 2.

\section{The mode of action of TRPV4 mutants}

The mode of action of the mutations in these TRPV4-related disorders has proved difficult to elucidate. Initial functional work investigating the impact of the mutations seen in the neuropathy group was conflicting, as both gain-of-function and loss-of-function mechanisms were proposed (Figures 4 and 5). This may have resulted from different 
experimental protocols, as each group studied different cell lines (HEK293, HeLa, Xenopus oocytes, and dorsal root ganglion cells). Further work by Fecto et al. investigated three of the TRPV4 neuropathy spectrum mutations in three cell types (HEK293, HeLa, and Neuro2a cells) and proposed that they caused the channels to have an increased channel open probability and an increased sensitivity to

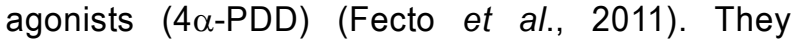
suggested that this observation could have resulted from a change in channel gating or increased membrane insertion of the channels (Deng et al., 2010; Fecto et al., 2011). Cell viability studies have shown a correlation with increased calcium influx and cytotoxicity that could be reversed by a TRPV4 channel inhibitor (ruthenium red; (Watanabe et al., 2002a)). Interestingly Loukin et al. studied 14 of the skeletal dysplasia-associated TRPV4 mutations in Xenopus oocytes and found evidence for increased open probability of the mutant channels (Loukin et al., 2010a; Loukin et al., 2011). Mutant channels also show increased sensitivity to channel agonists ( $4 \alpha-P D D$ and hypotonicity). They observed a correlation between increasing levels of channel open probability and phenotype severity (Loukin et al., 2010a; Loukin et al., 2011). Hence, mutations that result in the mildest phenotype, brachyolmia, cause an approximate $2 \%$ increase in channel open probability, whereas open probability of mutant channels causing the severe phenotype MTD approached $100 \%$. TRPV4 participates in terminal differentiation of developing osteoclasts by providing sustained calcium influx, but the mechanism by which these mutations cause the skeletal dysplasia remains unclear (Figure 4). Finally, functional studies of the TRPV4 mutations causing FDAB in HEK293 cells showed a small increase in channel open probability with a slight increase in sensitivity to channel agonists and reduced cell surface expression. The overall effect was thought to result in a reduction in channel activity (Figures 4 and 5 ).

The effects of these mutations on other factors such as protein folding, post translational glycosylation, protein-protein interactions, heterotetramerization, and protein trafficking may also contribute to the phenotypic expression of these TRPV4 mutations (Cuajungco et al., 2006; Wang et al., 2007; Fernandes et al., 2008; Ma et al., 2011). Consideration of the three-dimensional structure of the channel reveals that four key residues in the ARD (ankyrin repeat domains) (Table 3 ) associated with the neuropathy spectrum are surface mutations, not thought to affect protein folding. They cluster on the positively charged convex surface of the ARD and involve highly conserved arginine residues, whereas the skeletal dysplasia mutations affecting the ARD are situated on the concave surface and may interrupt the protein-protein interactions (Hellwig et al., 2005; Arniges et al., 2006). Thus, the mutations in each group of conditions may affect different protein functions, while overlapping conditions may result from mutations affecting residues involved in shared functions of the protein. TRPV4 forms homotetramers, but recent work has shown that it interacts with other channels including TRPC1 and TRPP2, forming heterotetramers with a 2:2 stoichiometry and alternating subunit arrangement results in distinct electrophysiological properties (Hellwig et al., 2005; Feng et al., 2011).

Further work has shown that TRPV4 interacts with the cytoskeleton and regulates microtubules and actin, which, in turn, is regulated by microtubule dynamics (Suzuki et al., 2003a; Ramadass et al., 2007; Shin et al., 2012). Thus, the full effects of the TRPV4 mutations may result from effects on additional functions of the protein not just on changes to the channel gating properties. Further studies are required to elucidate the pathogenic mechanisms occurring in these disorders and identify the genetic and environmental modifying factors that cause such striking variation in disease expression.

\section{Conclusion and perspective}

The TRPV4 functional $\mathrm{Ca}^{2+}$ channel consists of the homo tetramer subunits. TRPV4 and TRPC1 can co-assemble to form heteromeric TRPV4-C1 channels (Hellwig et al., 2005; Feng et al., 2011). Because the TRPV4 ankyrin repeat is responsible for channel self-assembly in cell lines, mutations in the TRPV4 ankyrin domain also seem to affect the channel assembly in humans, as shown in many dominant negative genetic disorders (Hellwig et al., 2005; Arniges et al., 2006).

TRPV4 was originally shown to be activated by hypotonicity, but later studies have demonstrated that activation can also be achieved by phorbol esters, arachidonic acid, and moderate heat (Guler et al., 2002; Watanabe et al., 2002a; Alessandri-Haber et al., 2003; Watanabe et al., 2003; Vriens et al., 2004; Birder et al., 2007). TRPV4 appears to be an important player in pathological sensory perception and bone growth. The potential effect of a TRPV4 functional mutation remains to be elucidated in the future. Furthermore, the role of TRPV4 in the pathogenesis of several diseases should be characterized as to how the channel protein contributes to the specific diseases. This information may be useful to cure or alleviate the human disease caused by TRPV4 mutations.

As expected, TRPV4 activation in osteoclasts 
increased the number of osteoclasts and their resorption activity, thereby resulting in bone loss. During in vitro analysis, TRPV4 ${ }^{\mathrm{R} 616 \mathrm{Q} / \mathrm{V} 6201}$ osteoclasts showed activated $\mathrm{Ca}^{2+} /$ calmodulin signaling compared with osteoclasts lacking TRPV4 (Mizoguchi et al., 2008; Rock et al., 2008; Everaerts et al., 2010). In addition, studies in TRPV4 ${ }^{\text {R616Q/V620I }}$ mice, which lack the calmodulin-binding domain, indicate that bone loss due to TRPV4 activation was abrogated by loss of interactions between $\mathrm{Ca}^{2+}$ / calmodulin signaling and TRPV4. Finally, modulators of TRPV4 interactions with the calmodulin-binding domain should be investigated by proteomic analysis (Tables 1 and 2).

Bones are constantly undergoing remodeling to adapt to mechanical stress, repair (micro) fractures, and regulate mineral metabolism (Mizoguchi et al., 2008; Abed et al., 2009; Masuyama et al., 2012). Mechanical stress plays an important role in bone formation and remodeling. Importantly, mechanical unloading of bones leads to the suppression of bone formation and increases bone resorption, as observed in bedridden patients that develop osteoporosis (Mizoguchi et al., 2008; Everaerts et al., 2010). As TRPV4 is expressed in both osteoblasts (responsible for bone deposition), and osteoclasts (mediate bone resorption), it may play a role in sensing mechanical stress and controlling bone remodeling (Mizoguchi et al., 2008; Abed et al., 2009; Masuyama et al., 2012). In mice, mechanical hind limb unloading induces osteopenia, reduces bone formation rate, and stimulates bone resorption by increasing the number of osteoclasts. In contrast, these effects are suppressed in TRPV4-/- mice (Mizoguchi et al., 2008). Moreover, TRPV4-/- mice show mild osteopetrosis, increased trabecular bone mineral density and increased cortical thickness, resulting from reduced bone resorption as a consequence of disrupted osteoclast differentiation (Figure 4). TRPV4-mediated $\mathrm{Ca}^{2+}$ influx plays a crucial role in $\mathrm{Ca}^{2+}$-dependent regulation of nuclear factor-activated $T$ cells $c 1$ (NFATc1), a transcription factor that controls osteoclast-specific gene expression (Masuyama et al., 2008).

TRPV4 in chondrocytes of cartilage tissue is involved in modulating chondrogenic bone formation by regulating sex determining region Y-box 9 (SOX9) activity (Muramatsu et al., 2007). SOX9 is a well-established chondrocyte transcription factor that regulates expression of cartilage-specific extracellular matrix proteins and controls chondrocyte differentiation and bone formation (Figure 4). TRPV4 stimulates SOX9-dependent reporter activity in mesenchymal stem cells via a $\mathrm{Ca}^{2+}$-calmodulin dependent mechanism. The role of TRPV4 requires further elucidation in the case of late chondrogenic differentiation, in which SOX9 functions as a negative regulator. Thus, it seems that TRPV4 mutants, which are constitutively active, maintain $\mathrm{Ca}^{2+}$ influx and its high concentration, resulting in activated NFATc1. As a consequence, osteoclast-specific gene expression is enhanced. The eventual phenotype of those mutants appears like SEDM (Figures 4 and 5 and Table 3).

Recent observations on endothelial cells (ECs) indicate that small numbers of EC TRPV4 channels regulate vascular physiology and suggest that pathologies characterized by blood pressure reduction and vascular permeability increases (e.g., septic shock) may involve excessive activation of EC TRPV4 channels (Sonkusare et al., 2012). These results demonstrate that a small number of active TRPV4 channels (about three to eight per cell) mediate local $\mathrm{Ca}^{2+}$ signals that activate the intermediate (IK)and the small (SK)-conductance, $\mathrm{Ca}^{2+}$-sensitive potassium $\left(\mathrm{K}^{+}\right)$channels to cause maximal dilation of resistance arteries. Similarly, in the chondrocyte, osteoblast, or osteoclast a small number of active TRPV4 channels mediate local $\mathrm{Ca}^{2+}$ signals that activate other channel such as IK and SK (Sonkusare et al., 2012). Even the increased ATP binding in E183K and E278K also contribute to constitutive TRPV4 activity, and the increase in TRPV4 activity seems to lead to TRPV4-linked spinal disease phenotypes (Phelps et al., 2010; Inada et al., 2012). Thus, the mutant TRPV4 channel that has increased activity in bone cells compared to normal causes a catastrophic effect, such as BRAC3, CMT2C, MTB, PSTD, or SEDM (Figures 4 and 5 and Table 3 ).

However, FDAB is not same as SEDM, because FDAB TRPV4 (G270V, R271P, Y273L) is not constitutively active compared to that of the TRPV4 WT. The mutation sites of FDAB TRPV4 are localized between ankyrin repeats 3 and 4 , which seem to be responsible for membrane localization. FDAB is caused by mutations encoding p.Gly270Val, p.Arg271Pro, and p.Phe273Leu substitutions in the intracellular ankyrin-repeat domain of the TRPV4 cation channel. The TRPV4 mutant that causes FDAB is poorly localized to the cell-surface in HEK-293 cells and shows reduced channel activity (Amor et al., 2002; Dai et al., 2010; Lamande et al., 2011; Loukin et al., 2011). Therefore, it is assumed that the TRPV4 mutant causes the different phenotypic diseases, depending on mutant TRPV4 channel activity (Figure 5). The balance between osteoblasts and osteoclasts seems to be regulated by TRPV4 activity (Figure 4). The only ambiguous mutant is the G806A (exon 5) mutation which causes both SMA/HMSN2C and CMT2C (Table 3). It is not clarified yet that the channel activity of TRPV4 $\mathrm{R} 269 \mathrm{H}$ is constitutively active or not (Amor et al., 
2002; Dai et al., 2010; Lamande et al., 2011; Loukin et al., 2011). It is not obvious why some mutations result in one phenotype over another but an intriguing possibility is that certain mutations associated with the neurological phenotype may predispose the TRPV4 transcript to act like no other TRPV isoform (trans-speciation) (Dai et al., 2010; Nishimura et al., 2010). Recent evidence also suggests that the mutations associated with a skeletal phenotype caused the increased calcium channel basal activity (Loukin et al., 2010a; Loukin et al., 2010b; Loukin et al., 2011). However, the same has been shown for mutations associated with the clear neurological phenotype (Deng et al., 2010; Fecto et al., 2011).

TRPV4 should be the first line of genetic investigation in any individual presenting with a predominant motor axonal neuropathy. Documentation of height and any skeletal complaints should also be determined. Those providing genetic counseling for these families need to be aware of the frequent occurrence of non-penetrance and the striking phenotypic variability (Bird, 1993; Dai et al., 2010). The importance of identifying the correct hereditary neuropathy subtype may have moved beyond prognostication and genetic counseling, as there is no treatment for these disorders, but the existence of known agonists and antagonists of the TRPV4 channel have prompted many suggestions that therapeutic pharmacological modification of the mutant channels may be possible.

Even though it is not completely accorded in all mutant cases yet, the mutant shown the more channel activity than the TRPV4 WT causes the abnormality of backbone morphogenesis (cause BRAC3, CMT2C, MTB, PSTD or SEDM), whereas the mutant shown the less channel activity than the TRPV4 WT causes the abnormality of articular morphogenesis or the neuropathy (FDAB or HMSN2C) (Figures 2 and 5 and Table 3). TRPV4 mutants are constitutively active and maintain high $\mathrm{Ca}^{2+}$ influx, resulting in activated NFATc1 and high osteoclast-specific gene expression (Wegierski et al., 2006). Thus, TRPV4 mutant causes the different phenotypic diseases, depending on the mutant TRPV4 channel activity. In addition, the balance of cell number between osteoblast and osteroclast seems to be regulated by the TRPV4 activity.

Several mutants studied in heterologous expression systems show constitutive basal activity and enhanced response to stimuli (Deng et al., 2010; Loukin et al., 2010a; Fecto et al., 2011; Loukin et al., 2011). These findings are consistent with cell death caused by high calcium influx such as the observed degeneration of motor neurons in neuropathies. However, it is difficult to explain how seemingly similar molecular properties lead to such diverse disease phenotypes.
It is essential to elucidate how TRPV4 is regulated at the molecular level to understand the mechanisms behind these inherited diseases.

Further studies are required to understand the pathogenic mechanisms occurring in these disorders and identify the modifying genetic and environmental factors that cause such striking variation in disease expression. The reason why TRPV4 mutations, which show greater constitutive activity and no change in unitary conductance or rectification, cause such prominent spinal diseases will be elucidated. Further, among 26 members of the TRP subfamily which are expressed in a broad range of tissues, why the only TRPV4 cation channel contributes to the generation of such many genetic bone diseases should be answered.

\section{Acknowledgements}

This work was supported by National Research Foundation of Korea (NRF) grants (2009-0076024 and 2009-0069007) funded by the Korea government (MEST) to S S Kang. We also appreciated The Core Facility of Chungbuk National University.

\section{References}

Abed E, Labelle D, Martineau C, Loghin A, Moreau R. Expression of transient receptor potential (TRP) channels in human and murine osteoblast-like cells. Mol Membr Biol 2009;26:146-58

Alessandri-Haber N, Yeh JJ, Boyd AE, Parada CA, Chen X, Reichling DB, Levine JD. Hypotonicity induces TRPV4mediated nociception in rat. Neuron 2003;39:497-511

Amor DJ, Tudball C, Gardner RJ, Lamande SR, Bateman JF, Savarirayan R. Familial digital arthropathy-brachydactyly. Am J Med Genet 2002;108:235-40

Andrade YN, Fernandes J, Vazquez E, Fernandez-Fernandez JM, Arniges M, Sanchez TM, Villalon M, Valverde MA. TRPV4 channel is involved in the coupling of fluid viscosity changes to epithelial ciliary activity. J Cell Biol 2005;168: 869-74

Andreucci E, Aftimos S, Alcausin M, Haan E, Hunter W, Kannu P, Kerr B, McGillivray G, McKinlay Gardner RJ, Patricelli MG, Sillence D, Thompson E, Zacharin M, Zankl A, Lamande SR, Savarirayan R. TRPV4 related skeletal dysplasias: a phenotypic spectrum highlighted byclinical, radiographic, and molecular studies in 21 new families. Orphanet J Rare Dis 2011;6:37

Arniges M, Fernandez-Fernandez JM, Albrecht N, Schaefer M, Valverde MA. Human TRPV4 channel splice variants revealed a key role of ankyrin domains in multimerization and trafficking. J Biol Chem 2006;281:1580-6

Auer-Grumbach M, Olschewski A, Papic L, Kremer H, McEntagart ME, Uhrig S, Fischer C, Frohlich E, Balint Z, Tang $B$, Strohmaier $H$, Lochmuller $H$, Schlotter-Weigel $B$, 
Senderek J, Krebs A, Dick KJ, Petty R, Longman C, Anderson $\mathrm{NE}$, Padberg GW, Schelhaas HJ, van Ravenswaaij-Arts CM, Pieber TR, Crosby AH, Guelly C. Alterations in the ankyrin domain of TRPV4 cause congenital distal SMA, scapuloperoneal SMA and HMSN2C. Nat Genet 2010;42:160-4

Becker D, Blase C, Bereiter-Hahn J, Jendrach M. TRPV4 exhibits a functional role in cell-volume regulation. J Cell Sci 2005;118:2435-40

Bird TD. Charcot-Marie-Tooth Neuropathy Type 2. 1993, University of Washingtion, Seattle, USA

Birder L, Kullmann FA, Lee H, Barrick S, de Groat W, Kanai A, Caterina M. Activation of urothelial transient receptor potential vanilloid 4 by 4 alpha-phorbol 12,13-didecanoate contributes to altered bladder reflexes in the rat. J Pharmacol Exp Ther 2007;323:227-35

Camacho N, Krakow D, Johnykutty S, Katzman PJ, Pepkowitz S, Vriens J, Nilius B, Boyce BF, Cohn DH. Dominant TRPV4 mutations in nonlethal and lethal metatropic dysplasia. Am J Med Genet A 2010;152A: 1169-77

Carreno FR, Ji LL, Cunningham JT. Altered central TRPV4 expression and lipid raft association related to inappropriate vasopressin secretion in cirrhotic rats. Am J Physiol Regul Integr Comp Physiol 2009;296:R454-66

Chen DH, Sul Y, Weiss M, Hillel A, Lipe H, Wolff J, Matsushita M, Raskind W, Bird T. CMT2C with vocal cord paresis associated with short stature and mutations in the TRPV4 gene. Neurology 2010;75:1968-75

Cho TJ, Matsumoto K, Fano V, Dai J, Kim OH, Chae JH, Yoo WJ, Tanaka Y, Matsui Y, Takigami I, Monges S, Zabel B, Shimizu K, Nishimura G, Lausch E, Ikegawa S. TRPV4-pathy manifesting both skeletal dysplasia and peripheral neuropathy: a report of three patients. Am J Med Genet A 2012;158A:795-802

Chun J, Shin SH, Kang SS. The negative feedback regulation of TRPV4 $\mathrm{Ca}(2+)$ ion channel function by its C-terminal cytoplasmic domain. Cell Signal 2012;24:1918-22

Cuajungco MP, Grimm C, Oshima K, D'Hoedt D, Nilius B, Mensenkamp AR, Bindels RJ, Plomann M, Heller $S$. PACSINs bind to the TRPV4 cation channel. PACSIN 3 modulates the subcellular localization of TRPV4. J Biol Chem 2006;281:18753-62

Dai J, Kim OH, Cho TJ, Schmidt-Rimpler M, Tonoki H, Takikawa K, Haga N, Miyoshi K, Kitoh H, Yoo WJ, Choi IH, Song HR, Jin DK, Kim HT, Kamasaki H, Bianchi P, Grigelioniene G, Nampoothiri S, Minagawa M, Miyagawa SI, Fukao T, Marcelis C, Jansweijer MC, Hennekam RC, Bedeschi F, Mustonen A, Jiang $Q$, Ohashi $H$, Furuichi T, Unger S, Zabel B, Lausch E, Superti-Furga A, Nishimura G, Ikegawa S. Novel and recurrent TRPV4 mutations and their association with distinct phenotypes within the TRPV4 dysplasia family. J Med Genet 2010;47:704-9

Delany NS, Hurle M, Facer P, Alnadaf T, Plumpton C, Kinghorn I, See CG, Costigan M, Anand P, Woolf CJ, Crowther D, Sanseau P, Tate SN. Identification and characterization of a novel human vanilloid receptor-like protein, VRL-2. Physiol Genomics 2001;4:165-74
Deng HX, Klein CJ, Yan J, Shi Y, Wu Y, Fecto F, Yau HJ, Yang Y, Zhai H, Siddique N, Hedley-Whyte ET, Delong R, Martina M, Dyck PJ, Siddique T. Scapuloperoneal spinal muscular atrophy and CMT2C are allelic disorders caused by alterations in TRPV4. Nat Genet 2010;42:165-9

Ding XL, Wang YH, Ning LP, Zhang Y, Ge HY, Jiang $H$, Wang $\mathrm{R}$, Yue SW. Involvement of TRPV4-NO-cGMP-PKG pathways in the development of thermal hyperalgesia following chronic compression of the dorsal root ganglion in rats. Behav Brain Res 2010;208:194-201

Earley S, Heppner TJ, Nelson MT, Brayden JE. TRPV4 forms a novel $\mathrm{Ca}^{2+}$ signaling complex with ryanodine receptors and BKCa channels. Circ Res 2005;97:1270-9

Everaerts W, Nilius B, Owsianik G. The vanilloid transient receptor potential channel TRPV4: from structure to disease. Prog Biophys Mol Biol 2010;103:2-17

Fecto F, Shi Y, Huda R, Martina M, Siddique T, Deng HX. Mutant TRPV4-mediated toxicity is linked to increased constitutive function in axonal neuropathies. J Biol Chem 2011;286:17281-91

Feng S, Rodat-Despoix L, Delmas P, Ong AC. A single amino acid residue constitutes the third dimerization domain essential for the assembly and function of the tetrameric polycystin-2 (TRPP2) channel. J Biol Chem 2011;286: 18994-9000

Fernandes J, Lorenzo IM, Andrade YN, Garcia-Elias A, Serra SA, Fernandez-Fernandez JM, Valverde MA. IP3 sensitizes TRPV4 channel to the mechano- and osmotransducing messenger 5'-6'-epoxyeicosatrienoic acid. J Cell Biol 2008; 181:143-55

Gevaert T, Vriens J, Segal A, Everaerts W, Roskams T, Talavera K, Owsianik G, Liedtke W, Daelemans D, Dewachter I, Van Leuven F, Voets T, De Ridder D, Nilius B. Deletion of the transient receptor potential cation channel TRPV4 impairs murine bladder voiding. J Clin Invest 2007; 117:3453-62

Guler AD, Lee H, lida T, Shimizu I, Tominaga M, Caterina M. Heat-evoked activation of the ion channel, TRPV4. J Neurosci 2002;22:6408-14

Hartmannsgruber V, Heyken WT, Kacik M, Kaistha A, Grgic I, Harteneck C, Liedtke W, Hoyer J, Kohler R. Arterial response to shear stress critically depends on endothelial TRPV4 expression. PLoS One 2007;2:e827

Hellwig N, Albrecht N, Harteneck C, Schultz G, Schaefer M. Homo- and heteromeric assembly of TRPV channel subunits. J Cell Sci 2005;118:917-28

Inada H, Procko E, Sotomayor M, Gaudet R. Structural and biochemical consequences of disease-causing mutations in the ankyrin repeat domain of the human TRPV4 channel. Biochemistry 2012;51:6195-206

Jia Y, Wang X, Varty L, Rizzo CA, Yang R, Correll CC, Phelps PT, Egan RW, Hey JA. Functional TRPV4 channels are expressed in human airway smooth muscle cells. Am J Physiol Lung Cell Mol Physiol 2004;287:L272-8

Kang SS. The mutation of transient receptor potential vanilloid 4 (TRPV4) cation channel in human diseases. 
Mutagenesis, 2012 InTech, Croatia in press

Kim KS, Shin DH, Nam JH, Park KS, Zhang YH, Kim WK, Kim SJ. Functional Expression of TRPV4 Cation Channels in Human Mast Cell Line (HMC-1). Korean J Physiol Pharmacol 2010;14:419-25

Krakow D, Vriens J, Camacho N, Luong P, Deixler H, Funari TL, Bacino CA, Irons MB, Holm IA, Sadler L, Okenfuss EB, Janssens A, Voets T, Rimoin DL, Lachman RS, Nilius B, Cohn $\mathrm{DH}$. Mutations in the gene encoding the calcium- permeable ion channel TRPV4 produce spondylometaphyseal dysplasia, Kozlowski type and metatropic dysplasia. Am J Hum Genet 2009;84:307-15

Lamande SR, Yuan Y, Gresshoff IL, Rowley L, Belluoccio D, Kaluarachchi K, Little CB, Botzenhart E, Zerres K, Amor DJ, Cole WG, Savarirayan R, McIntyre P, Bateman JF. Mutations in TRPV4 cause an inherited arthropathy of hands and feet. Nat Genet 2011;43:1142-6

Landoure G, Zdebik AA, Martinez TL, Burnett BG, Stanescu $\mathrm{HC}$, Inada H, Shi Y, Taye AA, Kong L, Munns $\mathrm{CH}$, Choo SS, Phelps CB, Paudel R, Houlden H, Ludlow CL, Caterina MJ, Gaudet R, Kleta R, Fischbeck KH, Sumner CJ. Mutations in TRPV4 cause Charcot-Marie-Tooth disease type 2C. Nat Genet 2010;42:170-4

Lee EJ, Shin SH, Hyun S, Chun J, Kang SS. The mudulation of TRPV4 channel activity through its 824 Ser residue phosphorylation by SGK1. Animal Cells Syst (Seoul) 2010;14:99-114

Lee EJ, Shin SH, Hyun S, Chun J, Kang SS. Mutation of a putative S-nitrosylation site of TRPV4 protein facilitates the channel activates. Animal Cells Syst (Seoul) 2011;15:95-106

Lewis $\mathrm{R}$, Feetham $\mathrm{CH}$, Barrett-Jolley R. Cell volume regulation in chondrocytes. Cell Physiol Biochem 2011;28: 1111-22

Li J, Kanju P, Patterson M, Chew WL, Cho SH, Gilmour I, Oliver T, Yasuda R, Ghio A, Simon SA, Liedtke W. TRPV4-mediated calcium influx into human bronchial epithelia upon exposure to diesel exhaust particles. Environ Health Perspect 2011;119:784-93

Loukin S, Su Z, Kung C. Increased basal activity is a key determinant in the severity of human skeletal dysplasia caused by TRPV4 mutations. PLoS One 2011;6:e19533

Loukin S, Su Z, Zhou X, Kung C. Forward genetic analysis reveals multiple gating mechanisms of TRPV4. J Biol Chem 2010a;285:19884-90

Loukin S, Zhou X, Su Z, Saimi Y, Kung C. Wild-type and brachyolmia-causing mutant TRPV4 channels respond directly to stretch force. J Biol Chem 2010b;285:27176-81

Ma X, Cheng KT, Wong CO, O'Neil RG, Birnbaumer L, Ambudkar IS, Yao X. Heteromeric TRPV4-C1 channels contribute to store-operated $\mathrm{Ca}(2+)$ entry in vascular endothelial cells. Cell Calcium 2011;50:502-9

Masuyama R, Mizuno A, Komori $H$, Kajiya $H$, Uekawa A, Kitaura H, Okabe K, Ohyama K, Komori T. Calcium/calmodulinsignaling supports TRPV4 activation in osteoclasts and regulates bone mass. J Bone Miner Res 2012;27:1708-21

Masuyama R, Vriens J, Voets T, Karashima Y, Owsianik G,
Vennekens R, Lieben L, Torrekens S, Moermans K, Vanden Bosch A, Bouillon R, Nilius B, Carmeliet G. TRPV4- mediated calcium influx regulates terminal differentiation of osteoclasts. Cell Metab 2008;8:257-65

McEntagart M. TRPV4 axonal neuropathy spectrum disorder. J Clin Neurosci 2012;19:927-33

Mizoguchi F, Mizuno A, Hayata T, Nakashima K, Heller S Ushida T, Sokabe M, Miyasaka N, Suzuki M, Ezura Y, Noda M. Transient receptor potential vanilloid 4 deficiency suppresses unloading-induced bone loss. J Cell Physiol 2008;216:47-53

Muramatsu S, Wakabayashi M, Ohno T, Amano K, Ooishi R, Sugahara T, Shiojiri S, Tashiro K, Suzuki Y, Nishimura R, Kuhara S, Sugano S, Yoneda T, Matsuda A. Functional gene screening system identified TRPV4 as a regulator of chondrogenic differentiation. J Biol Chem 2007;282: 32158-67

Nedungadi TP, Carreno FR, Walch JD, Bathina CS, Cunningham JT. Region-specific changes in transient receptor potential vanilloid channel expression in the vasopressin magnocellular system in hepatic cirrhosis-induced hyponatraemia. J Neuroendocrinol 2012;24:642-52

Nemec SF, Cohn DH, Krakow D, Funari VA, Rimoin DL, Lachman RS. The importance of conventional radiography in the mutational analysis of skeletal dysplasias (the TRPV4 mutational family). Pediatr Radiol 2012;42:15-23

Nilius B, Owsianik G. Channelopathies converge on TRPV4. Nat Genet 2010;42:98-100

Nilius B, Vriens J, Prenen J, Droogmans G, Voets T. TRPV4 calcium entry channel: a paradigm for gating diversity. Am J Physiol Cell Physiol 2004;286:C195-205

Nishimura G, Dai J, Lausch E, Unger S, Megarbane A, Kitoh $\mathrm{H}$, Kim OH, Cho TJ, Bedeschi F, Benedicenti F, MendozaLondono R, Silengo M, Schmidt-Rimpler M, Spranger J, Zabel B, Ikegawa S, Superti-Furga A. Spondylo-epiphyseal dysplasia, Maroteaux type (pseudo-Morquio syndrome type 2 ), and parastremmatic dysplasia are caused by TRPV4 mutations. Am J Med Genet A 2010;152A:1443-9

Obeidat M, Wain LV, Shrine N, Kalsheker N, Soler Artigas M, Repapi E, Burton PR, Johnson T, Ramasamy A, Zhao JH, Zhai G, Huffman JE, Vitart V, Albrecht E, IgI W, Hartikainen AL, Pouta A, Cadby G, Hui J, Palmer LJ, Hadley D, McArdle WL, Rudnicka AR, Barroso I, Loos RJ, Wareham NJ, Mangino M, Soranzo N, Spector TD, Glaser S, Homuth G, Volzke H, Deloukas P, Granell R, Henderson J, Grkovic I, Jankovic S, Zgaga L, Polasek O, Rudan I, Wright AF, Campbell H, Wild SH, Wilson JF, Heinrich J, Imboden M, Probst-Hensch NM, Gyllensten U, Johansson A, Zaboli G, Mustelin L, Rantanen T, Surakka I, Kaprio J, Jarvelin MR, Hayward C, Evans DM, Koch B, Musk AW, Elliott P, Strachan DP, Tobin MD, Sayers I, Hall IP. A comprehensive evaluation of potential lung function associated genes in the SpiroMeta general population sample. PLoS One 2011;6:e19382

Phelps CB, Wang RR, Choo SS, Gaudet R. Differential regulation of TRPV1, TRPV3, and TRPV4 sensitivity through a conserved binding site on the ankyrin repeat domain. J Biol Chem 2010;285:731-40 
Ramadass R, Becker D, Jendrach M, Bereiter-Hahn J. Spectrally and spatially resolved fluorescence lifetime imaging in living cells: TRPV4-microfilament interactions. Arch Biochem Biophys 2007;463:27-36

Shin SH, Lee EJ, Hyun S, Chun J, Kim Y, Kang SS. Phosphorylation on the Ser 824 residue of TRPV4 prefers to bind with F-actin than with microtubules to expand the cell surface area. Cell Signal 2012;24:641-51

Sonkusare SK, Bonev AD, Ledoux J, Liedtke W, Kotlikoff MI Heppner TJ, Hill-Eubanks DC, Nelson MT. Elementary $\mathrm{Ca}^{2+}$ signals through endothelial TRPV4 channels regulate vascular function. Science 2012;336:597-601

Strotmann R, Harteneck C, Nunnenmacher K, Schultz G, Plant TD. OTRPC4, a nonselective cation channel that confers sensitivity to extracellular osmolarity. Nat Cell Biol 2000;2:695-702

Strotmann R, Schultz G, Plant TD. $\mathrm{Ca}^{2+}$-dependent potentiation of the nonselective cation channel TRPV4 is mediated by a C-terminal calmodulin binding site. J Biol Chem 2003;278:26541-9

Suzuki M, Hirao A, Mizuno A. Microtubule-associated [corrected] protein 7 increases the membrane expression of transient receptor potential vanilloid 4 (TRPV4). J Biol Chem 2003a;278:51448-53

Suzuki M, Mizuno A, Kodaira K, Imai M. Impaired pressure sensation in mice lacking TRPV4. J Biol Chem 2003b;278: 22664-8

Tabuchi K, Suzuki M, Mizuno A, Hara A. Hearing impairment in TRPV4 knockout mice. Neurosci Lett 2005;382:304-8

Tian W, Fu Y, Garcia-Elias A, Fernandez-Fernandez JM, Vicente R, Kramer PL, Klein RF, Hitzemann R, Orwoll ES, Wilmot B, McWeeney S, Valverde MA, Cohen DM. A loss-of-function nonsynonymous polymorphism in the osmoregulatory TRPV4 gene is associated with human hyponatremia. Proc Natl Acad Sci USA 2009;106:14034-9

Unger S, Lausch E, Stanzial F, Gillessen-Kaesbach G, Stefanova I, Di Stefano CM, Bertini E, Dionisi-Vici C, Nilius B, Zabel B, Superti-Furga A. Fetal akinesia in metatropic dysplasia: The combined phenotype of chondrodysplasia and neuropathy? Am J Med Genet A 2011;155A:2860-4

Vennekens R, Owsianik G, Nilius B. Vanilloid transient receptor potential cation channels: an overview. Curr Pharm Des 2008;14:18-31

Verma P, Kumar A, Goswami C. TRPV4-mediated channelopathies. Channels (Austin) 2010;4:319-28

Voets T, Prenen J, Vriens J, Watanabe $H$, Janssens A, Wissenbach $U$, Bodding $M$, Droogmans $G$, Nilius $B$.
Molecular determinants of permeation through the cation channel TRPV4. J Biol Chem 2002;277:33704-10

Vriens J, Owsianik G, Fisslthaler B, Suzuki M, Janssens A, Voets T, Morisseau C, Hammock BD, Fleming I, Busse R, Nilius B. Modulation of the $\mathrm{Ca} 2$ permeable cation channel TRPV4 by cytochrome P450 epoxygenases in vascular endothelium. Circ Res 2005;97:908-15

Vriens J, Watanabe H, Janssens A, Droogmans G, Voets T, Nilius B. Cell swelling, heat, and chemical agonists use distinct pathways for the activation of the cation channel TRPV4. Proc Natl Acad Sci USA 2004;101:396-401

Wang Y, Fu X, Gaiser S, Kottgen M, Kramer-Zucker A, Walz $G$, Wegierski T. OS-9 regulates the transit and polyubiquitination of TRPV4 in the endoplasmic reticulum. $\mathrm{J}$ Biol Chem 2007;282:36561-70

Watanabe H, Davis JB, Smart D, Jerman JC, Smith GD, Hayes P, Vriens J, Cairns W, Wissenbach U, Prenen J, Flockerzi V, Droogmans G, Benham CD, Nilius B. Activation of TRPV4 channels (hVRL-2/mTRP12) by phorbol derivatives. J Biol Chem 2002a;277:13569-77

Watanabe H, Vriens J, Suh SH, Benham CD, Droogmans G, Nilius B. Heat-evoked activation of TRPV4 channels in a HEK293 cell expression system and in native mouse aorta endothelial cells. J Biol Chem 2002b;277:47044-51

Watanabe H, Vriens J, Prenen J, Droogmans G, Voets T, Nilius B. Anandamide and arachidonic acid use epoxyeicosatrienoic acids to activate TRPV4 channels. Nature 2003;424:434-8

Wegierski T, Hill K, Schaefer M, Walz G. The HECT ubiquitin ligase AIP4 regulates the cell surface expression of select TRP channels. EMBO J 2006;25:5659-69

Yoshida T, Inoue R, Morii T, Takahashi N, Yamamoto S, Hara Y, Tominaga M, Shimizu S, Sato Y, Mori Y. Nitric oxide activates TRP channels by cysteine S-nitrosylation. Nat Chem Biol 2006;2:596-607

Zhu G, Gulsvik A, Bakke P, Ghatta S, Anderson W, Lomas DA, Silverman EK, Pillai SG. Association of TRPV4 gene polymorphisms with chronic obstructive pulmonary disease. Hum Mol Genet 2009;18:2053-62

Zimon M, Baets J, Auer-Grumbach M, Berciano J, Garcia A, Lopez-Laso E, Merlini L, Hilton-Jones D, McEntagart M, Crosby AH, Barisic N, Boltshauser E, Shaw CE, Landoure G, Ludlow CL, Gaudet R, Houlden H, Reilly MM, Fischbeck $\mathrm{KH}$, Sumner CJ, Timmerman V, Jordanova A, Jonghe PD. Dominant mutations in the cation channel gene transient receptor potential vanilloid 4 cause an unusual spectrum of neuropathies. Brain 2010;133:1798-809 